\begin{tabular}{ccc}
\hline International Journal of Engineering \& Technology, $7(3.2)(2018) 285-290$ \\
SPC & Website: $w$ ww.sciencepubco.com/index.php/IJET \\
Research paper & Sechnology \\
\hline
\end{tabular}

\title{
Analysis and Prevention of Industrial Injury in the Construction Sector
}

\author{
Roman Pahomov ${ }^{1}$, Oleksandr Zyma ${ }^{2}$, Evgen Dyachenko ${ }^{3}$ \\ ${ }^{I}$ Poltava National Technical Yuri Kondratyuk University, Ukraine \\ ${ }^{2}$ Poltava National Technical Yuri Kondratyuk University, Ukraine \\ ${ }^{3}$ Poltava National Technical Yuri Kondratyuk University, Ukraine \\ *Corresponding Author E-Mail: Zymaae@Gmail.Com
}

\begin{abstract}
Industrial accidents with fatal consequences in Ukraine were investigated in the paper. International experience of injury prevention was briefly analyzed in the article. The dynamics of Industrial accidents with fatal consequences in Ukraine from 1992 to 2016 was considered. The main reasons that significantly affected the level of injury in the construction industry and in the building materials industry from 2013 to 2016 were identified and analyzed. Methods of analysis of accidents and occupational diseases at the workplace were considered. The forecast of accidents with fatal consequences for three years from 2017 to 2019 , with the usage of an one-factor forecast model on the basis of a trend logarithmic curve was developed. Recommendations for the prevention and reduction of the level of injury at the enterprises of the construction industry were developed.
\end{abstract}

Keywords: analysis, industrial injury, lethal injury, one-factor forecast model, prevention of accident.

\section{Introduction}

An emergency situation with the security and the working conditions occurred at the most enterprises, especially at medium and small business enterprises according to the economic, environmental and demographic crisis in Ukraine, events on the East of Ukraine.

The number of enterprises, both state and non-state forms of ownership, with harmful and dangerous working conditions increases annually. The underestimation, ignoring the right conditions creating factors for safe work causes irreparable damage to the health of workers, adversely affect the level of labor productivity.

The number of employees at the conditions that fail to meet the established requirements on labor protection increased from $15 \%$ up to $30 \%$ of the total number of employees in the recent years and for today is almost 3 million people.

According to the Office for National Statistics data, more than 1.5 million workers have been working under unsanitary conditions of increased air pollution at the workplace by chemicals, dust, excessive levels of noise and vibration, complexity and intensity of labor in recent years. In some enterprises, the number of employees working in unsatisfactory conditions is up to $2 / 3$ of their total number. At enterprises of some types of economic activity, the share of such employees is $77.4 \%$ (mining of coal and peat), $55.9 \%$ (production of coke and oil refining), $54.6 \%$ (production of metal-completed products).

According to the State Labor Service data, more than $70 \%$ of Ukrainian enterprises fail to meet the sanitary requirements regarding the operation of heating, ventilation, lighting and sanitary facilities for them.

Today, on average, almost every third employee works in harmful and dangerous working conditions.
There are devastating tendencies due to the deterioration of working conditions and the constant increase of occupational diseases level among the working age population of Ukrainians that lead to significant weakening of labor potential, worsening of the demographic situation in Ukraine. These are manifested by a decrease in the total number of able-bodied population, especially by a decrease in the proportion of the population of younger age groups as a reserve of labor potential.

The need for labor resources in the leading industrial sectors can be satisfied only by $38 . . .44 \%$ at such rates of irreversible deterioration of professional health in Ukraine in 2016...2020. This is fraught with a collapse of personnel supply of production, especially in such industrial sectors as metallurgy, chemical and coke-chemical, coal, mining, energy and construction.

\section{Analysis of Recent Research and Publications}

The workers are affected by many different factors in the conditions of the construction area. These factors create dangerous situations resulting in accidents and injuries. One of the conditions for reducing occupational injuries at building organizations is the study of this complex phenomenon. Its main goal is to identify and analyze the causes, their roles and interrelationships during the process of forming a dangerous situation.

Many scientific researches are devoted to the problem of analyzing the causes of industrial injuries.

Thus, the methods of analysis that are given in the works $[1 \ldots 4]$ practically characterize the purely administrative system of the labor protection management. A clear algorithm for conducting research is formulated by these methods: injuries data collection and analysis; determination of appropriate coefficients; drawing up of corresponding schedules and analysis of the results of 
calculations; development of preventive measures to reduce the level of industrial injuries.

The works [5 ...9] are devoted to issues of improving the work safety, analysis and prevention of injuries at particular industrial sectors. The organizational questions of safe work conduction on separate technological directions are considered on the basis of actual material. Algorithms of complex analysis of working conditions and the rate of injuries were proposed.

In papers $[10,11]$ the actual issues of the modern information technology and mathematical apparatus usage in solving the problems of management in the field of labor protection were considered. The algorithms of injuries modeling and predicting are offered, as well as the methodology for evaluating the effectiveness of management activity.

Despite the large number of conducted researches it can be stated, that existing methods and approaches to the analysis and forecasting of industrial injuries do not provide an aggregate picture of the problem. The variety of approaches to studying the causes of injuries indicates that there is no single, scientifically validated method of studying the injuries.

In this regard, it is important to improve the general approaches and methods of industrial injuries studying, to expand and detail them in accordance with the dynamical socio-economical conditions.

\subsection{The Purpose of the Paper}

The aim of the paper is to improve the methods of studying of industrial injuries with severe consequences and to develop a mathematical model for predicting the accidents at work.

\section{Basic Material and Results}

The analysis of injuries at work is one of the main and necessary ways of developing the mechanisms for prevention and exclusion of injuries. After all, an accident at work, especially with a lethal case, should be considered as a signal of an unsatisfactory state of preventive work on the exclusion of injuries at a particular production facility or at the production area as a whole. So, only after the definition of the work safety state in the industry, in the work, the objective identification of the real causes of an accident and the laws of its occurrence, there are real opportunities for an effective search for ways to intensify preventive work and reduce injuries.

For the whole world, construction is one of the leading and most important sectors of economy. Despite the achievements of mechanization and automation of technological processes, construction remains as an industry sector where a large number of workers are employed. The construction industry belongs to the type of economic activity where technological processes, equipment, and sometimes the working conditions are characterized by an increased danger to the workers. The enterprises of the construction industry and the construction materials industry account for a significant proportion of accidents from the total number of workers injured in the production area. Industrial injury has long been a topical issue in all countries of the world, including Ukraine. Traumatism is one of the most important medical and social problems of today for most countries of the world. Throughout the XX century the topicality of the problem of injuries at work increased. The increase of injuries with a lethal result, with the transition to disability, with a temporary loss of working capacity is noted. Today, in economically developed countries, injuries occupy the third place among the causes of the population death, especially among the working age. In the US, the construction sector employs about 5 ... $6 \%$ of the total workforce, and the share of industrial injuries reaches $15 \%$, which also exceeds similar indicators in other sectors of the economy. In Japan, the share of the construction complex accounts for $10 \%$ of all employed people, and $42 \%$ of industrial injuries that had a lethal result. In Sweden, similar figures are equal $6 \%$ and $13 \%$ respectively [12]. In recent years in Ukraine, the situation in the field of labor protection remains tense. The current system for labor protection managing has proved to be insufficiently effective in today's conditions. As a result, the level of industrial injuries remains rather high.

According to the International Labor Organization, more than 500 deaths in agriculture, industry and services sectors are recorded worldwide every day. Annually more than 300 thousand workers receive industrial injuries and professional diseases. Every three minutes, one worker dies as a result of an accident, and every second four workers receive an industrial injury. In the world, the economic losses associated with industrial injuries are about $1 \%$ of the world's gross national product.

Statistics show [13], that the distribution of injuries in the main industrial sectors over a number of years remains constant.

The dynamics of general industrial injuries in the six most dangerous industrial sectors of Ukraine from 2013 to 2016, (people) is shown in Figure 1.

Analysis of conducted research indicates that the main causes of lethal injuries in construction sector are:

$>$ execution of construction and installation works without a work execution project or low quality of this project;

$>$ the absence of a production base at an enterprise that could provide employees with equipment of collective and individual protection;

$>$ mass involvement to the work of unskilled workers;

$>$ the formalization of labor relations of a certain part of employees with violations of the requirements of the current legislation, and in some cases, these relations did not take place at all. A significant part of the employees of such enterprises did not pass the necessary training on labor protection, internship and preliminary medical examination. 


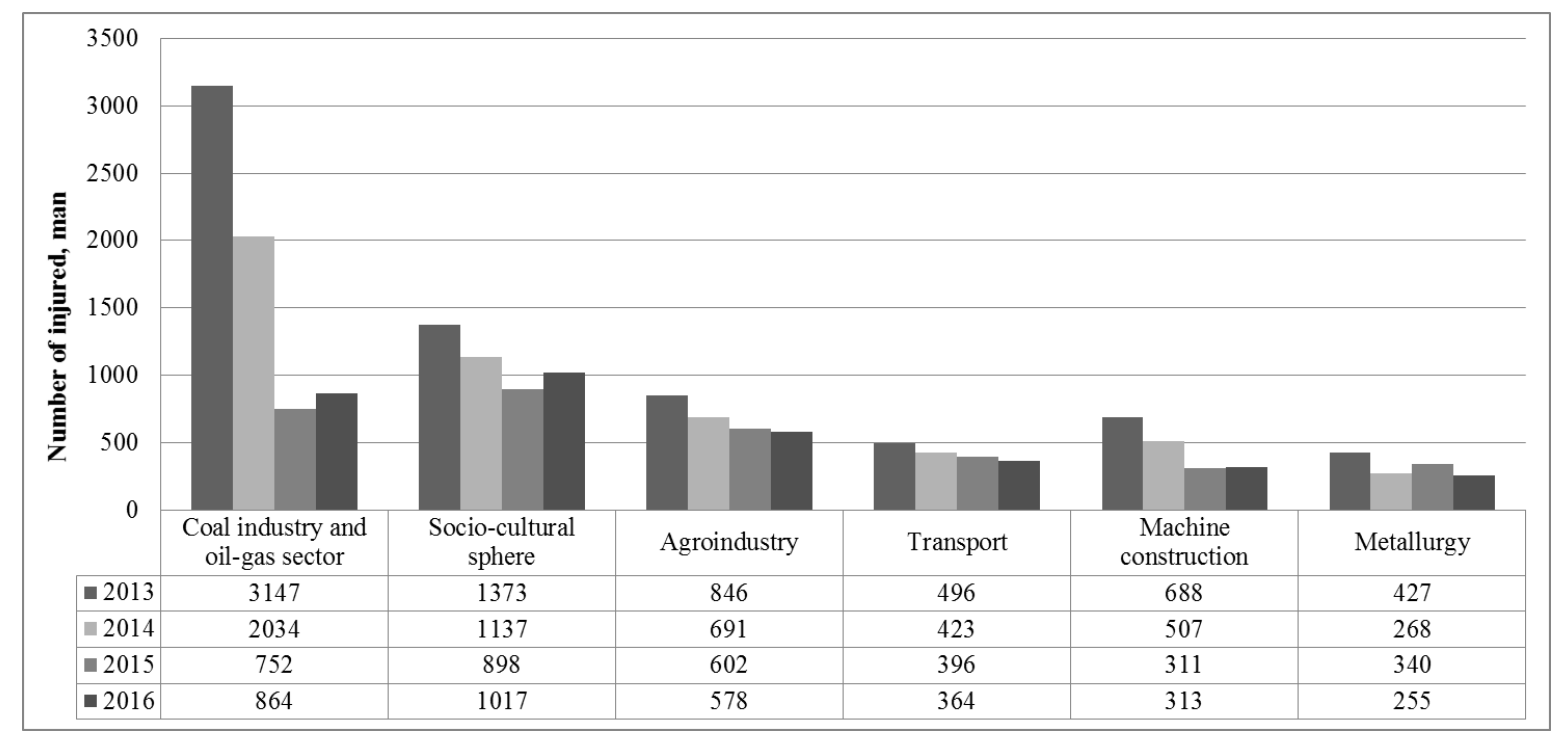

Fig. 1: Dynamics of general industrial injuries in the six most dangerous industrial sectors of Ukraine from 2013 to 2016, (people)

The spread of new technologies and the reduction of the worker skill level is the main cause of injuries with lethal consequences at the construction sector. The analysis shows that a significant number of accidents occurred due to unsatisfactory organization of workplaces located at a height. All this is due to the increase of the enhanced number of stories of frame-monolithic buildings construction, especially in large cities, and conduction production in a dense urban development. Workers on construction sites fall from the working surface of building structures, lifting facilities, hinged platforms and other technological equipment. The worker fall from the height is facilitated by the possibility of free access to the openings of elevator shafts, ventilation ducts and other technological openings. Subjective factor has a significant influence on the increase in the level of injuries, above all - noncompliance by employees of industrial and labor discipline.

Investigation of industrial injuries with lethal consequences was carried out on the basis of investigative materials based on the investigation acts, compiled according to the form $\mathrm{N}-1$, defined by the NPAOP 0.00-6.02-04 "Procedure for investigation and accounting of accidents, professional diseases and accidents at work".

The processing of data on industrial injuries for a certain period was carried out using the statistical method, which allowed to determine the dynamics of industrial injury changes and its severity in certain industrial sectors, to reveal regularities of increase or decrease of accident individual indicators.

Characteristics of changes in industrial injuries and lethal injuries from 1992 to 2016 are shown in the charts in Figure 2 and Figure 3.

Recently, there has been a positive trend towards reducing industrial and lethal injuries. In 1992, the total number of injuries were 124971 events, in 2016 - 4428 events. Total industrial injuries decreased by $96.5 \%$. The number of lethal injuries in 1992 were 2619 events, in 2016 - 400 events. The number of lethal events decreased by $84.7 \%$.

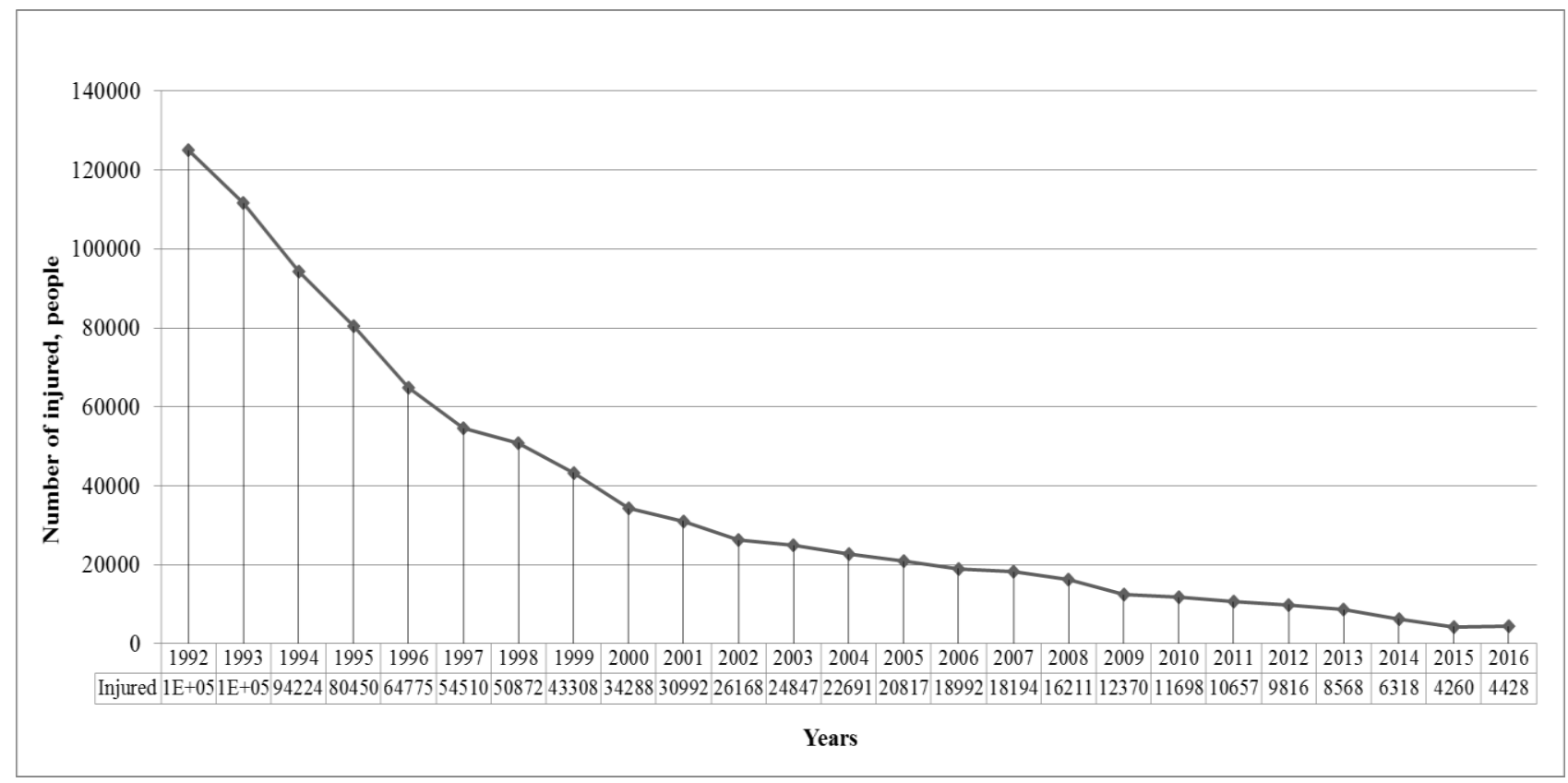

Fig. 2: Dynamics of total industrial injuries from 1992 to 2016, (people) 


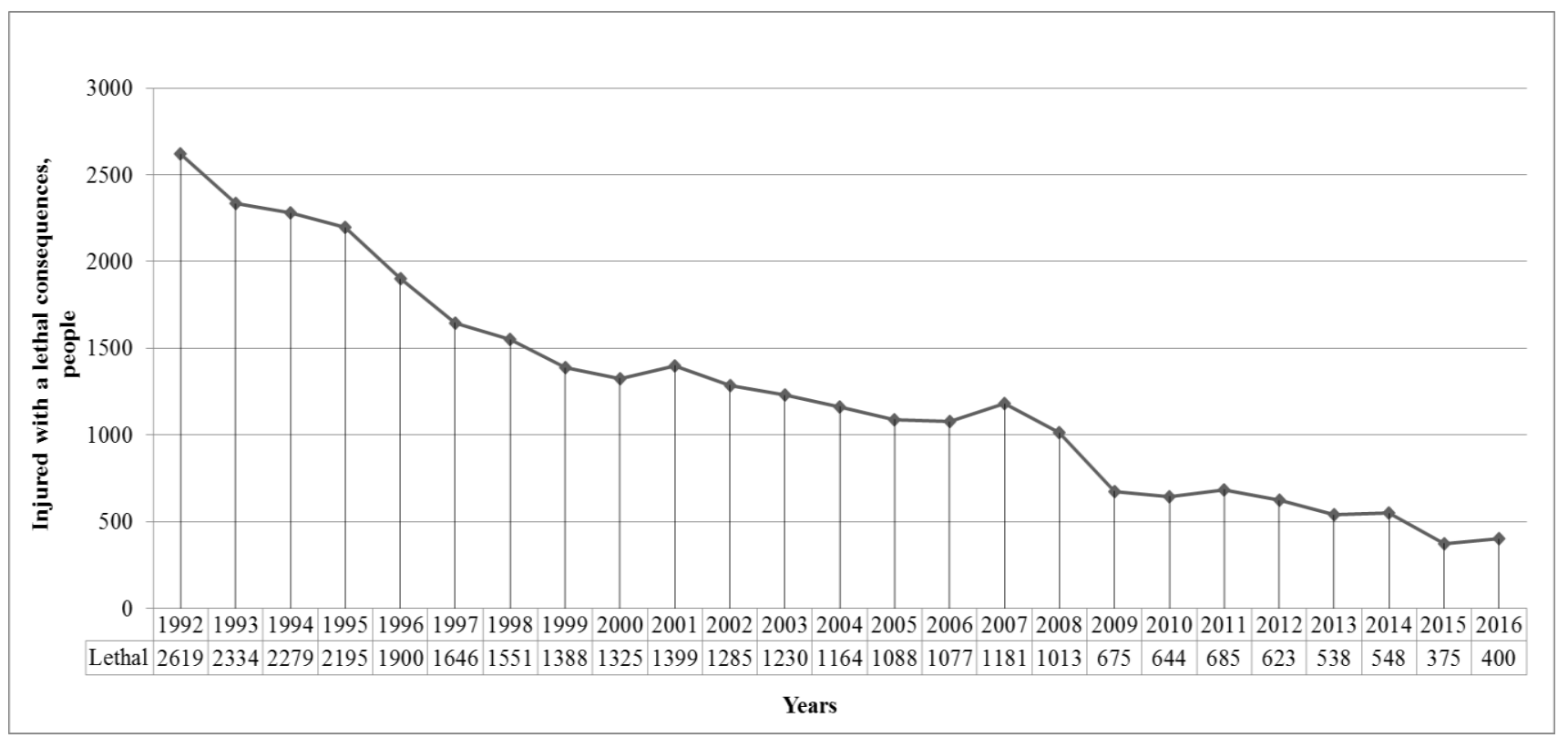

Fig. 3: Dynamics of lethal industrial injuries from 1992 to 2016, (people).

Positive changes in the dynamics of industrial injuries and professional diseases are largely due to: reduction of production volumes, part-time employment of workers, the labor flow from traumatic production to commercial and other non-productive sectors, incomplete account of injuries and professional diseases.

Successful prevention of industrial injuries and professional diseases is possible only with careful study of their occurrence causes. To facilitate this task it is accepted to share the causes of industrial injuries and professional diseases to the following main groups: organizational, technical, sanitary-hygienic, economic, and psychophysiological.

Organizational causes - lack of or low-quality training on the issues of labor protection; lack of control; violation of the requirements of instructions, rules, norms, standards; noncompliance with labor protection measures; violation of technological regulations, rules of operation of equipment, vehicles, tools; violation of norms and rules of planned and preventive repair of the equipment; insufficient technical supervision of dangerous work; the use of equipment, machinery and tools for other purposes.

Technical causes - failure of production equipment, mechanisms, tools; imperfection of technological processes; structural defects of the equipment, imperfections or absence of protective barriers, safety devices, devices of alarm and blocking.

Sanitary-hygienic causes - high content in the air of working zones of harmful substances, insufficient or irrational illumination; increased levels of noise, vibration; unsatisfactory microclimatic conditions; the presence of various radiation above the permissible values; violation of the rules of individual hygiene.

Psychophysiological causes - false actions as a result of the employee's fatigue due to excessive complexity and intensity of work; monotony of work; morbid condition of the employee; negligence; discrepancy between psycho-physiological or anthropometric worker's data and used technique or performed work.

Economic causes - irregular payment of salary; low earnings; irregularity of work; desire for overtime work; part-time work or work at two different enterprises.

Statistical data on industrial injuries at the enterprises of the construction sector of Ukraine show that the main causes of industrial accidents are organizational, technical and psychophysiological causes (Figure 4).

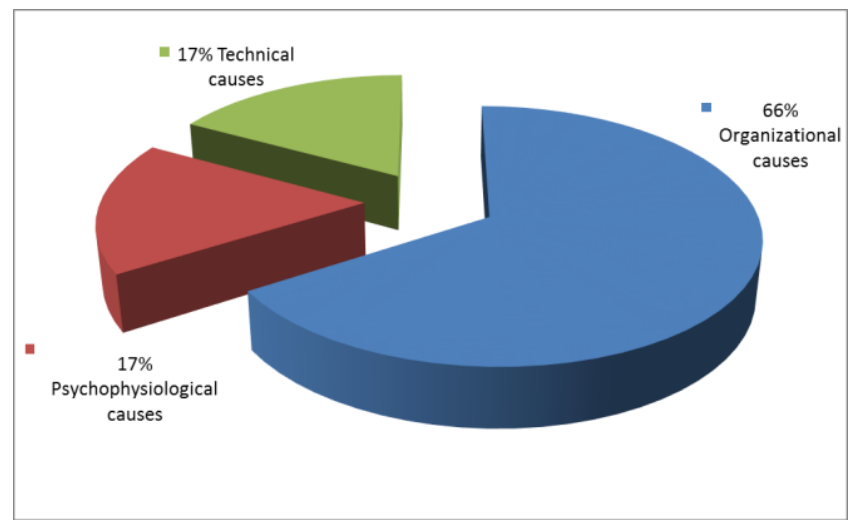

Fig. 4: Causes of industrial injuries at the enterprises of the construction sector

Only for organizational causes there are $60 \ldots 80 \%$ of all accidents in everyday life and production. But to improve the conditions of activity, increase security is impossible with the help of only organizational measures, it is necessary to implement certain technical measures.

In the system of measures on the prevention of industrial injuries, developed by all countries, an important role is devoted to the development and implementation of integrated labor safety programs.

One of such programs is the development of prognostic models of the injury level, as separate for economic activity, and for the country as a whole, which allows us to develop a plan of measures to improve working conditions for $3 \ldots 5$ years.

For the injuries prediction in Ukraine for the next 3 years onefactor forecast model was used. This method of analysis and forecasting of industrial injuries allows to develop preventive measures that take into account the mutual influence of various factors.

The most common method of forecasting is the analytic representation of the trend. At the same time for release outside of the time-period, it is enough to extend the value of the independent variable of time.

In this regard, the progress of the development associated with the passage of time, i.e.

$$
\bar{y}_{t}=f(t) .
$$

Such estimate is calculated by substituting the number of the year $t$, for which the forecast is calculated, into the trend equation. It is an average estimate for the predicted time interval. 
It is advisable to determine the confidence intervals of the forecast. The value of the confidence interval is determined as follows:

$$
\hat{y}_{t}= \pm t_{\alpha} \sigma_{y_{t}},
$$

where $\sigma_{y_{t}}$ - average quadratic error of the trend; $\hat{y}_{t}$ - estimated value of level; $t_{\alpha}-$ is the Student's criterion confidence parameter. The average quadratic deviation from trend is equal to:

$\sigma_{y}=\sqrt{\frac{\sum\left(y_{i}-\hat{y}_{i}^{*}\right)^{2}}{k}} ; \quad k=n-m$,

where $k-$ is the degree of freedom; $n-$ the number of observations; $m-$ the number of parameters; $t_{\alpha}-$ is the $\mathrm{t}-$ statistic's value.

To construct the trend line, the logarithmic curve is used:
To assess the adequacy of the model by using the least squares method, the least square value of the deviations of theoretical values from the empirical ones is determined.

$\sum\left(y_{t}-\hat{y}\right)^{2}=567620$.

Consequently, the polynomial of the first degree has the smallest value of the deviation's squares sum. Therefore, among these functions, the trend for given empirical data is the function:

$$
\hat{y}_{t}=2966 \cdot 74 \lg (t)
$$

To obtain predictive values for three periods $(\mathrm{L}=3)$ based on the constructed trend, the theoretical data extrapolation was completed.

The next result was received.

$\hat{y}_{t+1}^{*}=551 ; \quad \hat{y}_{t+2}^{*}=523 ; \quad \hat{y}_{t+3}^{*}=496$.

$\hat{y}=a_{0} \cdot a_{1} \lg (t)$.

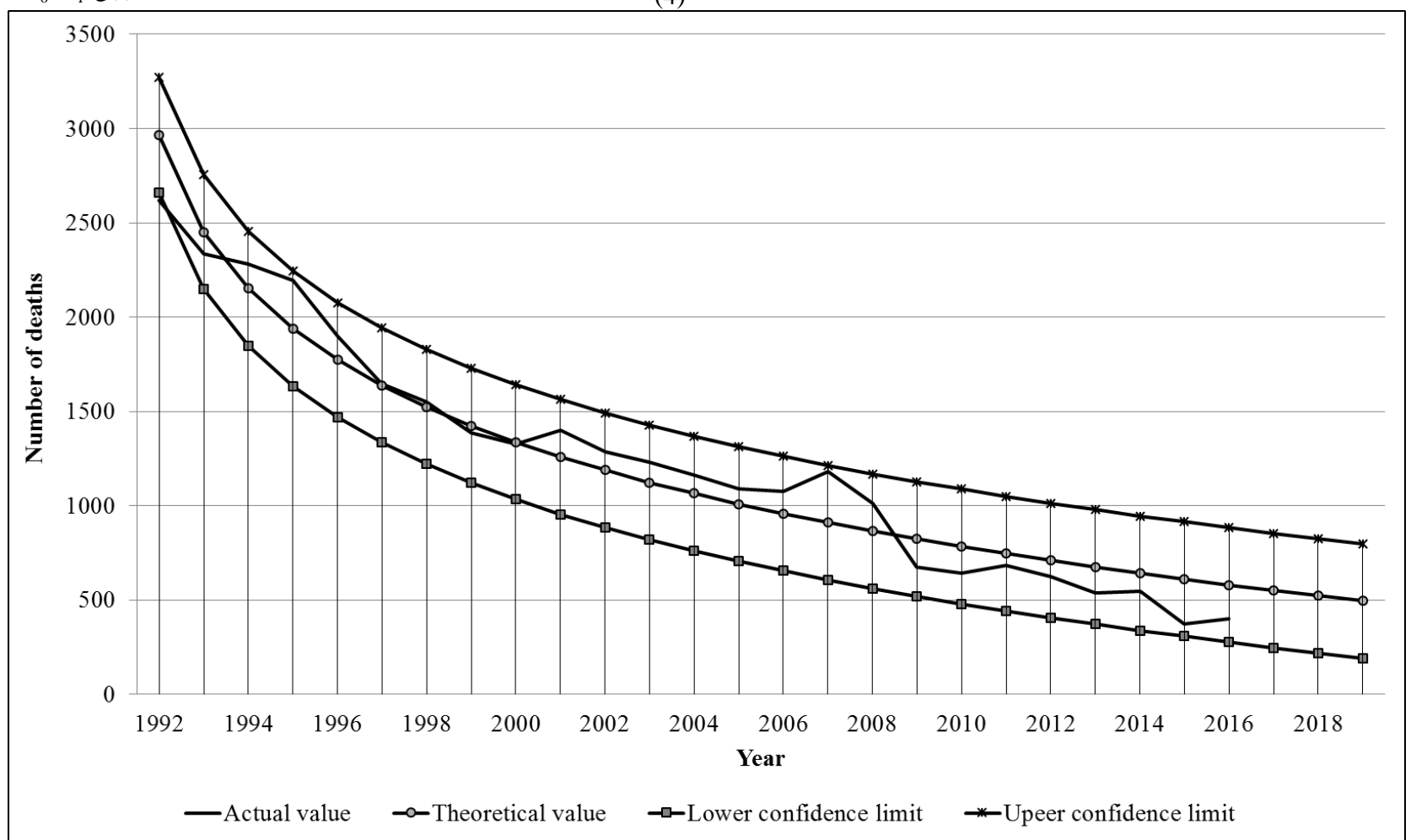

Fig. 5: The total lethal industrial injuries forecast for 2017-2019 years in Ukraine

Table 1:To the mean quadratic error of retrospective forecasts of lethal industrial injuries calculation

\begin{tabular}{|c|c|c|c|c|}
\hline Parameters & $\begin{array}{c}\text { Theoretical } \\
\text { value }\end{array}$ & $\begin{array}{c}\text { Actual } \\
\text { value }\end{array}$ & $\begin{array}{c}\text { Absolute } \\
\text { forecast } \\
\text { error }\end{array}$ & $\begin{array}{c}\text { Squared } \\
\text { error }\end{array}$ \\
\hline 1992 & 2966 & 2619 & -347 & 120409 \\
\hline 1993 & 2452 & 2334 & -118 & 13924 \\
\hline 1994 & 2152 & 2279 & 127 & 16129 \\
\hline 1995 & 1939 & 2195 & 256 & 65536 \\
\hline 1996 & 1773 & 1900 & 127 & 16129 \\
\hline 1997 & 1638 & 1646 & 8 & 64 \\
\hline 1998 & 1524 & 1551 & 27 & 729 \\
\hline 1999 & 1425 & 1388 & -37 & 1369 \\
\hline 2000 & 1338 & 1325 & -13 & 169 \\
\hline 2001 & 1259 & 1399 & 140 & 19600 \\
\hline 2002 & 1189 & 1285 & 96 & 9216 \\
\hline 2003 & 1124 & 1230 & 106 & 11236 \\
\hline 2004 & 1065 & 1164 & 99 & 9801 \\
\hline 2005 & 1010 & 1088 & 78 & 6084 \\
\hline 2006 & 959 & 1077 & 118 & 13924 \\
\hline & & & & \\
\hline
\end{tabular}

\begin{tabular}{|c|c|c|c|c|}
2007 & 911 & 1181 & 270 & 72900 \\
\hline 2008 & 866 & 1013 & 147 & 21609 \\
\hline 2009 & 824 & 675 & -149 & 22201 \\
\hline 2010 & 784 & 644 & -140 & 19600 \\
\hline 2011 & 746 & 685 & -61 & 3721 \\
\hline 2012 & 710 & 623 & -87 & 7569 \\
\hline 2013 & 675 & 538 & -137 & 18769 \\
\hline 2014 & 642 & 548 & -94 & 8836 \\
\hline 2015 & 611 & 375 & -236 & 55696 \\
\hline 2016 & 580 & 400 & -180 & 32400 \\
\hline
\end{tabular}

The mean square deviation from the trend (3) equals $\sigma_{y}=147.8$ $(n=25, m=2)$. Also, determine the value of the $t$ - Student's statistic criterion (with a confidence probability 0.95 ) $t_{\alpha}=2.06$ [14].

The calculations are shown in Table 1. The graph of the forecast is shown in Figure 5.

The performed calculations conditionally allow to assert further reduction of the lethal industrial injuries level as a whole in the 
Ukrainian industry, as well as in the construction sector and the building materials production sector.

\section{Conclusions}

The analysis of injuries in the Ukrainian construction sector shows that most accidents occur in small just-created small businesses, which mostly have no qualified specialists in the labor protection system. Some recently created construction companies, after obtaining a license for construction activities, avoid obtaining in accordance with the law of Ukraine "On labor protection" the permission of the State Labor Service of Ukraine to start work and operation of objects, machines, mechanisms and equipment of high danger. The leaders of such organizations do not pass training and verification of knowledge on labor protection, and sometimes do not even have the appropriated professional training.

During the analysis of accidents, it was discovered that injuries are the result of violations of normative legal acts on occupational safety, namely:

$>$ insecurity of the workers or their non-use of individual and collective protective equipment during the work at a height execution;

> execution of construction and installation works by organizations that do not have the State Construction Agency license and the State Labor Service of Ukraine authorization for the beginning of the high danger works execution;

$>$ execution of construction and installation works in accordance to the low-quality work execution projects or in case of their absence;

$>$ admission to the work of officials and not-qualified workers, who did not pass training and knowledge verification of relevant normative acts on labor protection and work placement training.

Problematic issues in the industry are:

$>$ uncertainty at the legislative level of the customer's or investor's responsibility on the general condition of labor protection at construction sites;

$>$ execution of work`s construction and installation without the work execution projects or for its low quality;

$>$ improper functioning of the labor protection system at enterprises;

$>$ low organizational level of enterprises, especially with a small number of employees in the absence of a production base, lack of collective and individual protection equipment, lack of sanitary and hygienic conditions;

$>$ involvement to the duties performance the specialists who do not have the appropriate level of qualification, who did not pass: training and verification of knowledge on labor protection (or passed it formally) and mass involvement in the construction of unskilled workers whose labor relations are formalized via civil-legal contracts, and in some cases not designed at all;

$>$ enterprises and organizations managers` low responsibility level for violations on labor protection.

The considered method of analysis and forecasting of industrial injuries allows to develop preventive measures taking into account the mutual influence of various factors.

The forecast shows that in 2017 there can be 551 accidents with lethal consequences, in 2018 - 523, and in $2019-496$ accidents.

These significant potential human losses (theoretical) encourage more active work on the prevention and prophylaxis of injuries in the workplace.

According to the opinion of International Labor Organization experts, the unsatisfactory state of labor protection in Ukraine is caused by the following factors:

$>$ lack of proper control over the work safety state at workplaces and compliance with established norms;

$>$ the slow introduction of progressive and safe technological processes;

deterioration (up to 80\%) of technological equipment;

$>$ insufficient role of the state in the organization, financing and control of the labor protection system.

Conducted researches allow to solve these questions partially. In addition, these calculations can be used in expert support for the development and implementation of labor protection system at enterprises of the construction sector, workplaces certification at enterprises, as well as in developing of the plan for comprehensive measures to improve the employees' working conditions of construction companies.

\section{References}

[1] Melik-Shahnazarov LSh, Popova TO, "Investigation of industrial injuries in Ukraine", Labor Protection Newsletter, No.3, (2006), pp: 9-13.

[2] Slipko OO, Duchkina JuV, "Comprehensive analysis of occupational injuries and measures to prevent accidents at the enterprises of the coal, mining and non-metallic industry of Ukraine", Labor Protection Newsletter, No.4, (2006), pp: 7-20.

[3] Degtyarenko GE, Romanenko NV, Leskovets VI, "The state of non-productive injuries in Ukraine", Bulletin of the National Research Institute of Labor Protection, No.7, (2004), pp: 33-35.

[4] Marucci-Wellman HR, Courtney TK, Corns HI, Sorock GS, Webster BS, Wasiak R, Noy YI, Matz S, Leamon TB, "The direct cost burden of 13 years of disabling workplace injuries in the U.S. (1998-2010): Findings from the Liberty Mutual Workplace Safety Index" Journal of Safety Research, Vol.55, (2015), pp: 53-62.

https://doi.org/10.1016/j.jsr.2015.07.002.

[5] Kostenko OM, Improvement of methods and tools for complex analysis, forecast and prevention of industrial injuries in agricultural production: author's abstract to PhD dissertation. Specialty 05.26.01 "Labor protection", Kyiv, (2002), 24 p.

[6] Rybalka KA, Improvement of labor safety at the reconstruction of one-storey industrial buildings: author's abstract to PhD dissertation. Specialty 05.26.01 "Labor protection", Dnipropetrovs`k, (2009), $20 \mathrm{p}$.

[7] Lebeau M, Duguay P, Boucher A, Costs of occupational injuries and diseases in Québec, Journal of Safety Research, Vol.50, (2014), pp. $89-98$

https://doi.org/10.1016/j.jsr.2014.04.002.

[8] Kazan E, Usmen MA, Worker safety and injury severity analysis of earthmoving equipment accidents, Journal of Safety Research Vol.65, (2018), pp. 73-81.

https://doi.org/10.1016/j.jsr.2018.02.008

[9] Graves JM, Vavilala MS, Rivara FP, The burden of traumatic brain injury among adolescent and young adult workers in Washington State, Journal of Safety Research, Vol.45, (2013), pp. 133-139.

https://doi.org/10.1016/j.jsr.2012.11.001

[10] Tkachuk KN, Kruzhylko OE, Prognosis of industrial injuries. monograph, Kyiv: Osnova, (2014), 345 p.

[11] Wang B, Wu C, Shi B, Huang L, Evidence-based safety (EBS) management: A new approach to teaching the practice of safety management (SM), Journal of Safety Research, Vol.63. (2017), pp. $21-28$

https://doi.org/10.1016/j.jsr.2017.08.012.

[12] Andrienko VM, Features of safety of work at the construction sphere in order to increase the level of economic safety of construction enterprises [Electronic resource].

Access:

http://www.rusnauka.com/2 KAND_2014/Economics/10 155927.d oc.htm

[13] The level of occupational injuries in Ukraine [Electronic resource]. Access:

http://otipb.at.ua/load/ctan_virobnichogo_travmatizmu_v_ukrajini_ za_12 misjaciv 2016 roku/24-1-0-5271.

[14] Derevyanskiy VJu, Lyubovskiy JuS, Forecast of industrial injuries on mine belt conveyors, Journal Coal of Ukraine, No.3, (2007), pp $8-30$. 